\title{
Factors Influencing the Safety and Efficiency of Antifungal Prophylaxis with Posaconazole in Children with Hematological Diseases: From Genetics to Polypharmacotherapy
}

\author{
Beata Sienkiewicz-Oleszkiewicz ${ }^{1}$ (D) Kamila Urbańczyk $^{1} \cdot$ Mateusz Stachowiak $^{2}$ • \\ Anna Rodziewicz ${ }^{2} \cdot$ Aleksander Zięba $^{1} \cdot$ Krzysztof Kałwak $^{2} \cdot$ Anna Wiela-Hojeńska $^{1}$
}

Received: 3 October 2018/Accepted: 6 May 2019/Published online: 14 May 2019

(C) The Author(s) 2019

\begin{abstract}
The aim of this study was to determine the impact of ABCB1 polymorphism, BMI, age and drug coadministration on safety and efficiency of posaconazole (PCZ) oral suspension treatment in children with hematological diseases. Seventy children were included in the study. ABCB1 polymorphism in fifty-eight children was determined using a PCR-RFLP method. A protocol with data on the health condition, treatment and adverse events (AE), as well as a survey on treatment tolerance for the legal guardians was evaluated. Liver function tests were observed for the first 20 days, and AE during the complete medication period. For statistical analysis a $\chi^{2}$ test with Yates's correction, a Pearson's or Spearman's correlation test was performed $(p<0.05)$. Genetic testing showed $24 \% \mathrm{CC}, 46 \% \mathrm{CT}$ and $30 \%$ of TT variants. PCZ prophylaxis failed in twenty cases, where change in prophylactic treatment was needed. Fifty-two children suffered from at least one mild to moderate adverse event. Sixty-five legal guardians completed the survey, most of them reported the treatment to be well tolerated. ABCB1 polymorphism had no impact on $\mathrm{AE}$ occurrence and posaconazole prophylaxis efficiency. Age influenced the number of gastrointestinal $(p=0.02)$, visual $(p=0.05)$, neurological $(p=0.01)$, dermatological $(p=0.002)$ and flu-like $(p=0.02)$ complications. AST $(p=0.03)$ and $\operatorname{LDH}(p=0.008)$ activity
\end{abstract}

Beata Sienkiewicz-Oleszkiewicz

beata.sienkiewicz-oleszkiewicz@umed.wroc.pl

1 Department of Clinical Pharmacology, Faculty of Pharmacy, Wrocław Medical University, 211a Borowska St., 50-556 Wrocław, Poland

2 Department of Paediatric Bone Marrow Transplantation, Oncology and Hematology, Wrocław Medical University, 213 Borowska St., 50-556 Wrocław, Poland presented age dependency. The concomitant use of proton pump inhibitors (PPI) had impact on liver health parameters elevation $(p=0.009)$ and circulatory system complications $(p=0.008)$. High incidence of mild to moderate $\mathrm{AE}$, and other factors influencing PCZ pharmacokinetics (PPI co-administration, obesity), suggest a need for careful pediatric onco-hematology patient evaluation.

Keywords ABCB1 protein - Adverse drug event . Children · Posaconazole $\cdot$ Hematology

\section{Introduction}

Posaconazole (PCZ) is a triazole antifungal agent. The drug is primarily indicated for molds infection prophylaxis in patients receiving chemotherapy for acute myeloid leukemia (AML), myelodysplastic syndrome (MDS) and in patients after allogenic hematopoietic stem cell transplantation (allo-HSCT).

It may also be used for treatment of particular cases of invasive aspergillosis, fusariosis, chromoblastomycosis, coccidioidomycosis and candidiasis $[1,2]$.

The treatment of children is very specific. Not only from the psychological point of view, also the pharmacokinetic properties of drugs differ from the adult population. Basic alterations are gathered in Table $1[3,4]$.

According to the Food and Drug Administration (FDA) PCZ oral formulation is approved for children older than $13[2,3]$. Some studies showed that the agent is also safe in children younger than 12 [5]. Although posaconazole has either no grading (in cases of children after allo-HSCT without GVHD) or a BI grade (in children after allo-HSCT with GVHD and in de novo or recurrent leukemias) according to the Recommendations for primary 
Table 1 Factors influencing drug pharmacokinetics in pediatric population [3, 4]

\begin{tabular}{|c|c|c|c|}
\hline Absorption & Distribution & Metabolism & Excretion \\
\hline $\begin{array}{l}\downarrow \text { Surface of } \\
\text { gastrointestinal tract } \\
\downarrow \text { HCl secretion } \\
\downarrow \text { Motility and } \\
\text { peristalsis } \\
\downarrow \text { Gastric emptying } \\
\downarrow \text { Bile secretion } \\
\text { Immature enzymes } \\
\text { Thinner stratum } \\
\text { corneum } \\
\uparrow \text { Hydration of } \\
\text { epidermidis } \\
\text { Variable skeletal } \\
\text { muscle blood flow }\end{array}$ & $\begin{array}{l}\uparrow \text { Total body water } \\
\uparrow \text { Extracellular water } \\
\downarrow \text { Fat content } \\
\uparrow \text { Body water: fat ratio } \\
\downarrow \text { Protein serum levels, } \\
\text { especially albumins } \\
\downarrow \alpha_{1} \text {-Glycoprotein } \\
\text { concentration } \\
\downarrow \text { Protein binding } \\
\uparrow \text { Permeability of brain- } \\
\text { blood barrier }\end{array}$ & $\begin{array}{l}\downarrow \text { CYP3A7 after birth, barely measurable in adults } \\
\downarrow \text { CYP2D6 (20\% of adult activity at } 1 \text { month of postnatal age, } \\
\text { adult competence-3-5 years of age) } \\
\downarrow \text { CYP2C9, CYP2C19 (low activity during the first week of life, } \\
\text { adult activity-6 months of age) } \\
\downarrow \text { CYP1A2 (adult levels }-4 \text { months of age, in children } 1-2 \text { years } \\
\text { of age may be exceeded) } \\
\downarrow \text { CYP3A4 (low activity in the first month of life, adult levels- } \\
6-12 \text { months postnatally) } \\
\downarrow N \text {-acetyltransferase } 2 \text { (NAT2) (adult activity } 1-3 \text { years of age) } \\
\downarrow \text { Uridine diphoshoglucuronyltransferase (UDP-GT) (adult } \\
\text { activity-6-18 months of age) }\end{array}$ & $\begin{array}{l}\downarrow \text { Glomerular } \\
\text { filtration rate } \\
\downarrow \text { Renal tubular } \\
\text { absorption }\end{array}$ \\
\hline
\end{tabular}

chemoprophylaxis of invasive fungal diseases in paediatric patients with cancer or haemopoietic stem-cell transplantation of the ECIL-4, it is often used in clinic for antifungal prophylaxis in children with hematological malignances [6].

The pediatric onco-hematology population is particularly exposed to adverse drug reactions (ADR) and adverse events (AE). The effectiveness and safety of PCZ oral suspension is influenced mainly by food intake, gastric $\mathrm{pH}$ and motility as well as drug-drug interactions [5, 7, 8]. Posaconazole is a substrate for UDP-glucuronosyltransferase and P-glycoprotein, thus agents having impact on these two clearance pathways must be taken into consideration during PCZ medication [1].

As P-glycoprotein is encoded by the ABCB1 gene, the polymorphism of which is connected with changes in the protein expression, the aim of our study was to determine the impact of ABCB1 polymorphism on the safety and efficiency of posaconazole oral suspension treatment in children. We also took into consideration other agents potentially influencing antifungal prophylaxis (BMI, age, drug co-administration). To our knowledge it is the first of this kind study performed among the Polish pediatric population with hematological diseases.

\section{Materials and Methods}

The study was performed according to the Declaration of Helsinki and with approval of the Bioethics Committee of the Wrocław Medical University (KB-657/2012). It is a single center, non-randomized retrospective analysis of seventy pediatric patients who received posaconazole oral suspension for antifungal prophylaxis.

\section{Patients Characteristics}

The included children were patients of the Paediatric Bone Marrow Transplantation, Oncology and Hematology Unit, of the Wrocław Medical University Hospital, aged between 2 months and 19 years. The median PCZ dose was $8 \mathrm{mg}$ per $\mathrm{kg}$ of body weight, two times a day according to the algorithm evaluated by Welzen et al. [9]. Most important data on patients enrolled is presented in Table 2.

Table 2 Patient characteristics

\begin{tabular}{lc}
\hline Characteristic & Number of patients (\%) \\
\hline Gender & \\
Male & $43(61.4)$ \\
Female & $27(38.6)$ \\
Age (median) [years] - median (25Q- & $7(2.0-14.0)$ \\
75Q) & \\
$<6$ & $32(45.7)$ \\
$7-11$ & $14(20)$ \\
$>12$ & $24(34.3)$ \\
Diagnosis & \\
ALL & $23(32.8)$ \\
AML & $18(25.7)$ \\
SAA & $8(11.4)$ \\
WAS & $4(5.7)$ \\
Other hematological diseases & $16(24.4)$ \\
BMI $\left[\mathrm{kg} / \mathrm{m}^{2}\right]$ - median (25Q-75Q) & $16.4(14.3-18.6)$ \\
$<18.5$ & $51(72.8)$ \\
$18.5-25$ & $17(24.3)$ \\
$>25$ & $2(2.9)$ \\
\hline
\end{tabular}

$A L L$ acute lymphoid leukemia, $A M L$ acute myeloid leukemia, $S A A$ serious aplastic anemia, WAS Wiskott-Aldrich Syndrome 


\section{Patients' Protocol and Survey}

A protocol with most important data on patients health condition, underlying diseases, allo-HSCT performance, previous infections, treatment and adverse events was evaluated. As posaconazole may lead to hepatic impairment we also monitored biochemical parameters of liver function. Those were aspartate aminotransferase (AST), alanine transaminase (ALT), activated partial thromboplastin time (APTT), gamma-glutamyltransferase (GGT), lactate dehydrogenase (LDH) activity, albumin and fibrinogen concentrations at three time points (before, at the seventh, and the twentieth day) of PCZ prophylaxis.

Drug-drug interactions are also factors influencing PCZ pharmacokinetics and inducing $\mathrm{AE}$ occurrence. So, we tried to determine, on the basis of patients treatment history, drugs potentially interacting with the antifungal agent. We monitored AE during the complete posaconazole conducted medication period.

In addition a survey on treatment tolerance and observed adverse events was evaluated and performed among the legal guardians of the examined children. Sixty-five of them completed the questionnaire.

The survey consisted of five parts: first-connected with basic information (body weight (BW), age, height), second-with information on previous fungal infections (occurred before hospital admission), third-potential food supplement administration, fourth-adverse events observed during posaconazole treatment (we intentionally listed AE possibly occurring during PCZ therapy) and fifth-concerning the treatment satisfaction in a 0-5 score scale. On this scale 0 meant no opinion, 1-no satisfaction (serious fungal infection occurred despite posaconazole prophylaxis), 2-low satisfaction (local fungal infection in more than one body area occurred), 3-moderate satisfaction (local fungal infection occurred), 4-satisfaction (no fungal infection, but adverse events occurred), 5-full satisfaction (no fungal infection and good tolerance).

\section{DNA Isolation and Genetic Testing}

We collected seventy samples (one from each patient) of whole blood drawn on EDTA. The samples were stored at $20{ }^{\circ} \mathrm{C}$.

DNA was isolated using the QIAamp ${ }^{\circledR}$ DNA Blood Mini Kit according to the manufacturer instruction, in a laminar flow cabinet.

For ABCB1 polymorphism determination, an adapted Siegmund et al. [10] polymerase chain reaction-restriction length polymorphism (PCR-RFLP) method was used.

\section{Statistical Analysis}

We performed statistical analysis on the collected data. For every group the number of cases $(\mathrm{N})$, median $(\mathrm{M})$, range (min-max), upper and lower quartile (25Q-75Q) was calculated. The hypothesis on the equality of median values of the groups was verified using the Kruskal-Wallis test.

For discrete parameters the frequency of features in the groups was analyzed using the Chi squared test with Yates's correction, with an adequate number of degrees of freedom $d f(d f=(\mathrm{m}-1) *(\mathrm{n}-1))$.

For chosen pairs of parameters a Pearson's or Spearman's correlation test was performed.

$p$ values less than 0.05 were considered statistically significant. $p$ values between 0.05 and 0.1 were considered as tendency. The statistical analysis was performed using the EPIINFO program (Ver. 7.1.1.14, 2013, USA).

\section{Results}

Seventy patients of the Paediatric Bone Marrow Transplantation, Oncology and Hematology Unit, of the Wrocław Medical University Hospital were included in our study. The median BMI was $16.4 \mathrm{~kg} / \mathrm{m}^{2}$, two children were overweight. During the observation period 21 (30\%) children suffered from acute GVHD, seven of them further developed a chronic form of the disease.

Fifty-eight legal guardians agreed for genetic testing of their children. The performed C3435T genetic testing for ABCB1 polymorphisms showed that $24 \%(\mathrm{~N}=14)$ of patients presented the $\mathrm{CC}, 46 \%(\mathrm{~N}=27)$ the $\mathrm{CT}$, and $30 \%$ $(\mathrm{N}=17)$ the TT variant.

Posaconazole oral formulation prophylaxis failed in 20 cases, where a change in treatment was needed according to suspected IFI development.

Fifty-two children suffered from at least one mild to moderate adverse event during invasive fungal infection prophylactic treatment. However according to the performed survey legal guardians reported the treatment to be well tolerated by their children (number of completed surveys 65 ; score $5 \mathrm{~N}=21$, score $4 \mathrm{~N}=21$, score $3 \mathrm{~N}=10$, score $2 \mathrm{~N}=2$, score $1 \mathrm{~N}=0$, score $0 \mathrm{~N}=11$ ). There was no need to discontinue posaconazole prophylaxis due to adverse events in any case. The occurrence of AE among different systems is presented in Fig. 1.

Increased AST activity was observed in 35 cases, ALT activity increased in 42, GGT in 28 cases. Nine children presented higher bilirubin values. Most frequent gastrointestinal disturbances were vomiting $(\mathrm{N}=29)$, nausea $(\mathrm{N}=25)$, loss of appetite $(\mathrm{N}=22)$, diarrhea $(\mathrm{N}=21)$, constipation $(\mathrm{N}=20)$ and abdominal pain $(\mathrm{N}=20)$. Dermatological complication manifested as mouth ulceration 
Fig. 1 Adverse events considered with PCZ prophylaxis in children

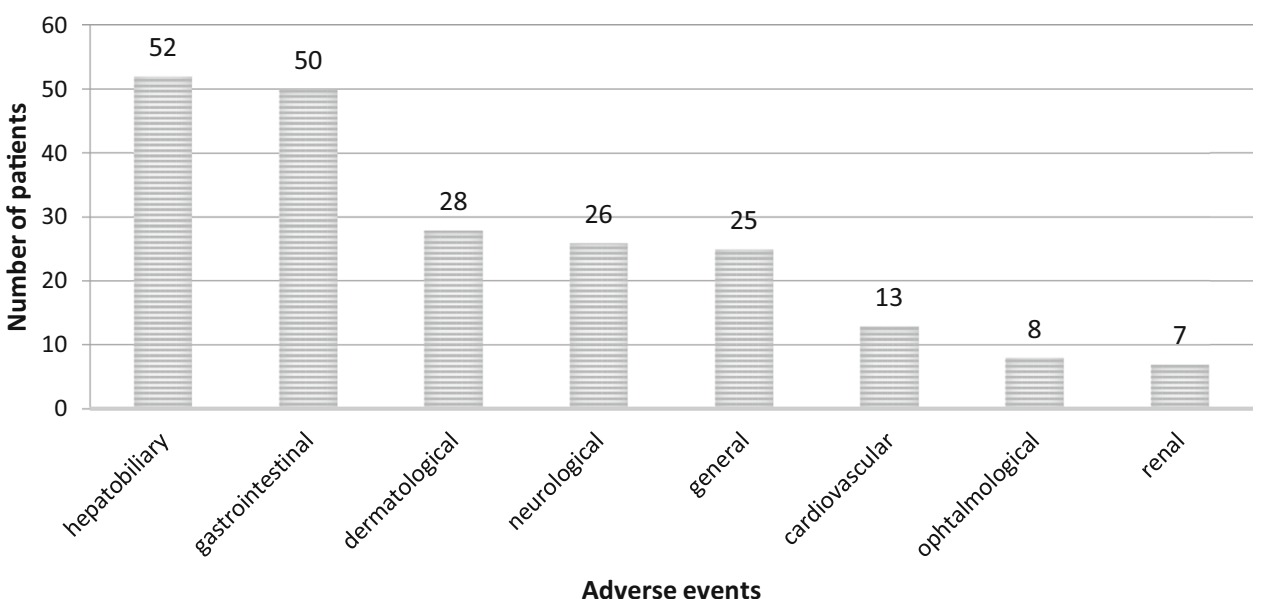

Table 3 Drugs potentially interacting with posaconazole during concomitant use

\begin{tabular}{ll}
\hline Drug/pharmacologic group & $\begin{array}{l}\text { Number of children receiving } \\
\text { the drug }(\%)\end{array}$ \\
\hline Calcineurin inhibitors & $52(74.3)$ \\
Biseptol & $52(74.3)$ \\
Acyclovir & $50(71.4)$ \\
Analgetics & $40(57.1)$ \\
Methotrexate & $39(55.7)$ \\
Ciprophloxacin & $33(47.1)$ \\
Proton pump inhibitors & $20(28.6)$ \\
Antiemetic's & $20(28.6)$ \\
Vincristine & $9(12.9)$ \\
Amlodypine & $5(7.1)$ \\
Anxiolytics & $3(4.3)$ \\
Fluconazole & $2(2.9)$ \\
\hline
\end{tabular}

$(\mathrm{N}=24)$ and rash $(\mathrm{N}=11)$. Nervous system disorders showed as headache $(\mathrm{N}=10)$, insomnia $(\mathrm{N}=7)$ and tremor $(\mathrm{N}=5)$. Ophthalmological disorders most often were connected with blurred vision $(\mathrm{N}=9)$ whereas cardiovascular disorders with hypertension $(\mathrm{N}=6)$. Renal disorders manifested as blood urea concentration increase in 5 and hemorrhagic cystitis in 2 cases.

Drug-drug interaction analysis led to determination of agents potentially inducing AE occurrence during PCZ treatment, having impact on its pharmacokinetic properties. Drugs and number of children treated are presented in Table 3.

Statistical analysis showed that ABCB1 polymorphism has no impact on overall adverse event occurrence and posaconazole prophylaxis efficiency as presented in Table 4. However two patients with good tolerance to posaconazole, who did not suffer from any adverse event during antifungal treatment presented the $\mathrm{CC}$ variant. We found a tendency for APTT prolongation during treatment in individuals presenting the TT variant $(p=0.07$, $\chi^{2}=8.45$ ). After twenty days of posaconazole treatment the APTT prolonged in four patients presenting the CT variant $(\mathrm{N}=27,14.8 \%)$, one patient with $\mathrm{CC}$ variant $(\mathrm{N}=14,0.07 \%)$ and in 7 patients presenting the TT variant $(\mathrm{N}=17,41.2 \%)$.

The age of children influenced the number of gastrointestinal, visual, neurological, dermatological and flu-like complications. The older the child the more often mentioned AE occurred. Furthermore AST and LDH activity presented age dependency especially in the first week of PCZ treatment.

Children with higher BMI values were more susceptible for visual and skin disturbances $(p=0.057, \mathrm{H}=3.61)$ as well as increased LDH activity during the first week of IFI prophylaxis.

Gender did not influence AE frequency.

The concomitant use of proton pump inhibitors (PPI) had great impact on parameters for liver health elevation and circulatory system complications during PCZ prophylaxis.

Most important findings on variables influencing adverse events during posaconazole conducted prophylaxis and their statistical significance are presented in Table 5.

\section{Discussion}

The aim of this investigation was to determine the impact of ABCB1 polymorphism, BMI, age and drug co-administration on safety and efficiency of posaconazole oral suspension treatment in children with hematological diseases.

In our study the frequencies of $\mathrm{ABCB} 1 \mathrm{C} 3435 \mathrm{~T}$ genetic variants (24\% for CC, $46 \%$ for CT and $30 \%$ for the TT variant) were comparable with other research performed among the Polish hematology population [11, 12]. 
Table 4 Influence of ABCB1 polymorphism on adverse events occurrence during posaconazole prophylaxis

\begin{tabular}{|c|c|c|c|c|c|c|c|}
\hline \multirow[t]{2}{*}{ Adverse event } & \multicolumn{2}{|c|}{$\mathrm{CT} \mathrm{N}=27(46 \%)$} & \multicolumn{2}{|c|}{$\mathrm{TT} \mathrm{N}=17(30 \%)$} & \multicolumn{2}{|c|}{$\mathrm{CC} \mathrm{N}=14(24 \%)$} & \multirow{2}{*}{$\begin{array}{l}\mathrm{P} \\
\left(\chi^{2}\right)\end{array}$} \\
\hline & 0 & 1 & 0 & 1 & 0 & 1 & \\
\hline Gastrointestinal disturbances & 7 & 20 & 5 & 12 & 4 & 10 & $\begin{array}{l}0.964 \\
(0.0724)\end{array}$ \\
\hline Ophthalmological disturbances & 22 & 5 & 16 & 1 & 13 & 1 & $\begin{array}{l}0.369 \\
(1.99)\end{array}$ \\
\hline Elevation of liver function parameters & 3 & 24 & 3 & 13 & 4 & 9 & $\begin{array}{l}0.313 \\
(2.32)\end{array}$ \\
\hline Neurological disturbances & 16 & 11 & 11 & 6 & 10 & 4 & $\begin{array}{l}0.741 \\
(0.600)\end{array}$ \\
\hline Dermatological changes & 16 & 11 & 9 & 8 & 9 & 5 & $\begin{array}{l}0.812 \\
(0.416)\end{array}$ \\
\hline Renal function changes & 25 & 2 & 15 & 2 & 12 & 2 & $\begin{array}{l}0.770 \\
(0.522)\end{array}$ \\
\hline General symptoms & 17 & 10 & 10 & 7 & 10 & 4 & $\begin{array}{l}0.762 \\
(0.543)\end{array}$ \\
\hline Cardiovascular disturbances & 21 & 6 & 13 & 4 & 12 & 2 & $\begin{array}{l}0.790 \\
(0.472)\end{array}$ \\
\hline Invasive fungal infection & 21 & 6 & 13 & 4 & 7 & 7 & $\begin{array}{l}0.148 \\
(3.821)\end{array}$ \\
\hline
\end{tabular}

0—no adverse event occurred

1 -adverse event occurred

We evaluated the influence of $\mathrm{ABCB} 1$ polymorphism on adverse event occurrence in children with hematological malignances treated with PCZ oral suspension. We found no statistical correlation, however a tendency for APTT prolongation during treatment was observed. This finding is completely new and to our knowledge has not been observed in any research before.

What is also interesting in our study, is that patients with good tolerance to posaconazole and with proper prophylactic response $(\mathrm{N}=2)$ presented the $\mathrm{CC}$ variant. This may be connected with higher activity of P-gp in patients with this $\mathrm{ABCB} 1$ genetic polymorphism, that was previously reported in patients with $\mathrm{B}$ cell chronic lymphocytic leukemia, and what comes along with the increased active transport of drugs out of cells, suggesting and supporting the thesis of a protective role of the $\mathrm{C} 3435 \mathrm{C}$ variant [12].

We didn't find a correlation between ABCB1 polymorphism and efficiency of PCZ prophylaxis measured as success or failure of prophylactic treatment. To our knowledge we were the first to evaluate this problem.

During posaconazole pharmacotherapy relatively high incidence of mild to moderate adverse events occurred. Most frequent were gastrointestinal, visual, neurological, dermatological and flu-like complications. The observations are concise with those from other studies. Lehrnbecher et al. [13] reported fever, nausea and/or vomiting, abdominal pain, diarrhea, headache, and skin eruptions as most common during PCZ treatment. Gastrointestinal and skin adverse events, according the observations of Döring et al. [5], were the most common complications.

The elevation of liver function tests namely transaminase activity and LDH activity is a well-known adverse drug reaction caused by triazole antifungal agents $[1,5,13-15]$. What is a new finding, and as to our knowledge was not observed in any of the previous studies in children, is a statistically significant correlation between age and mentioned AE. The older the child the more often described adverse events occurred. A similar tendency was observed for adults, where a reduction in the apparent volume of distribution, and $11 \%$ higher average plasma posaconazole concentration were observed according to older age [16]. However as children generally have different pharmacokinetics than adults, this finding cannot be directly extrapolated into the pediatric population.

The concomitant use of proton pump inhibitors (omeprazole, pantoprazole) had impact on parameters for liver health and circulatory system complications during PCZ prophylaxis. The influence of concomitant PPI administration with posaconazole is well established for the adult population and was also evaluated in children [7, 16-19]. Although in general the PPI co-administration is connected with lower posaconazole serum 
Table 5 Most important findings on variables influencing adverse events during posaconazole treatment and their statistical significance

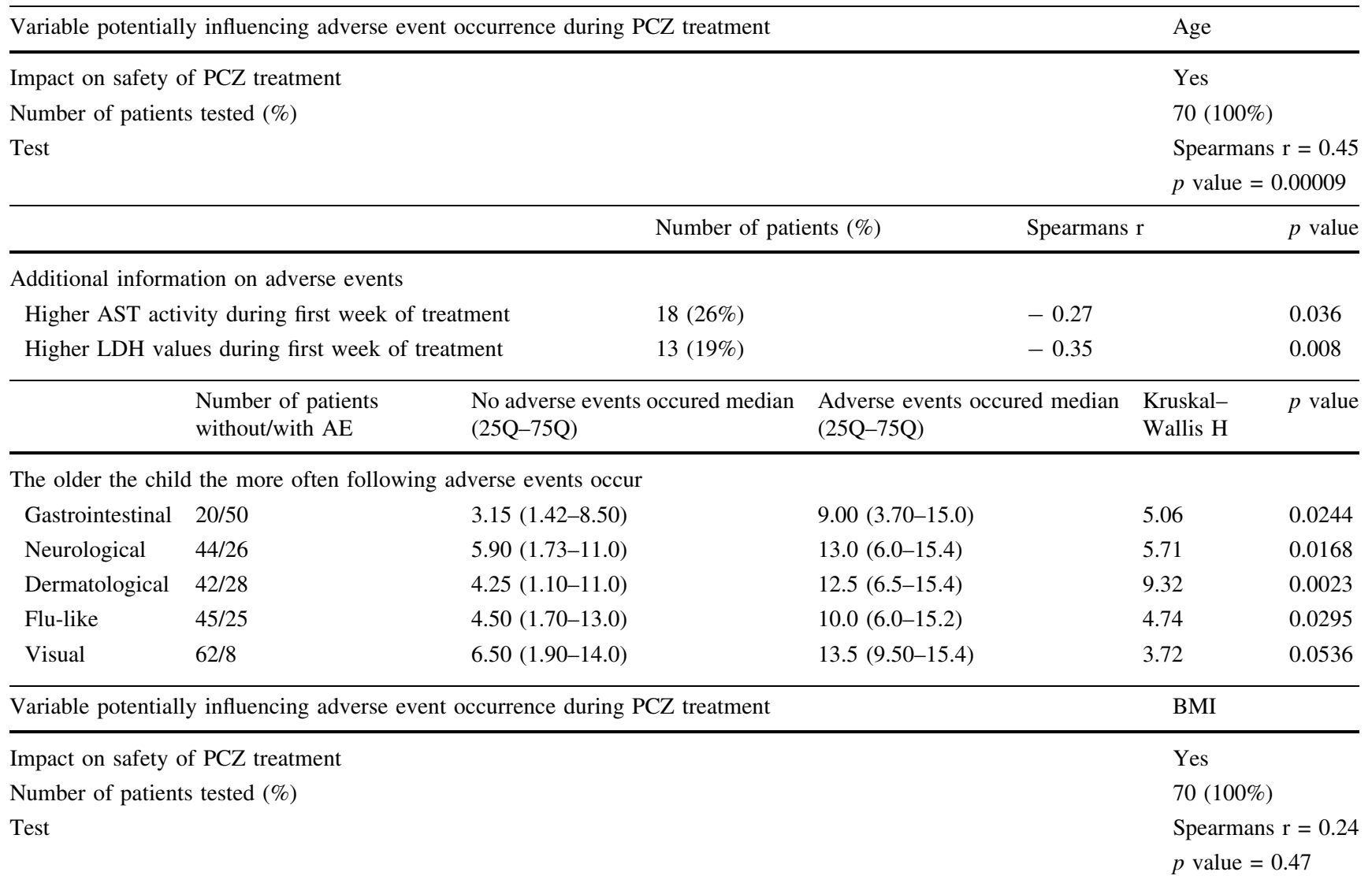

\begin{tabular}{llll}
\hline & Number of patients (\%) & Spearmans r & $p$ value \\
\hline
\end{tabular}

Additional information on adverse events

Increased LDH activity during first week of treatment

$13(19 \%)$

$-0.35$

0.01

Variable potentially influencing adverse event occurrence during PCZ treatment

Concomitant PPI administration

Impact on safety of PCZ treatment

Yes

Number of patients tested (\%)

$64(91 \%)$

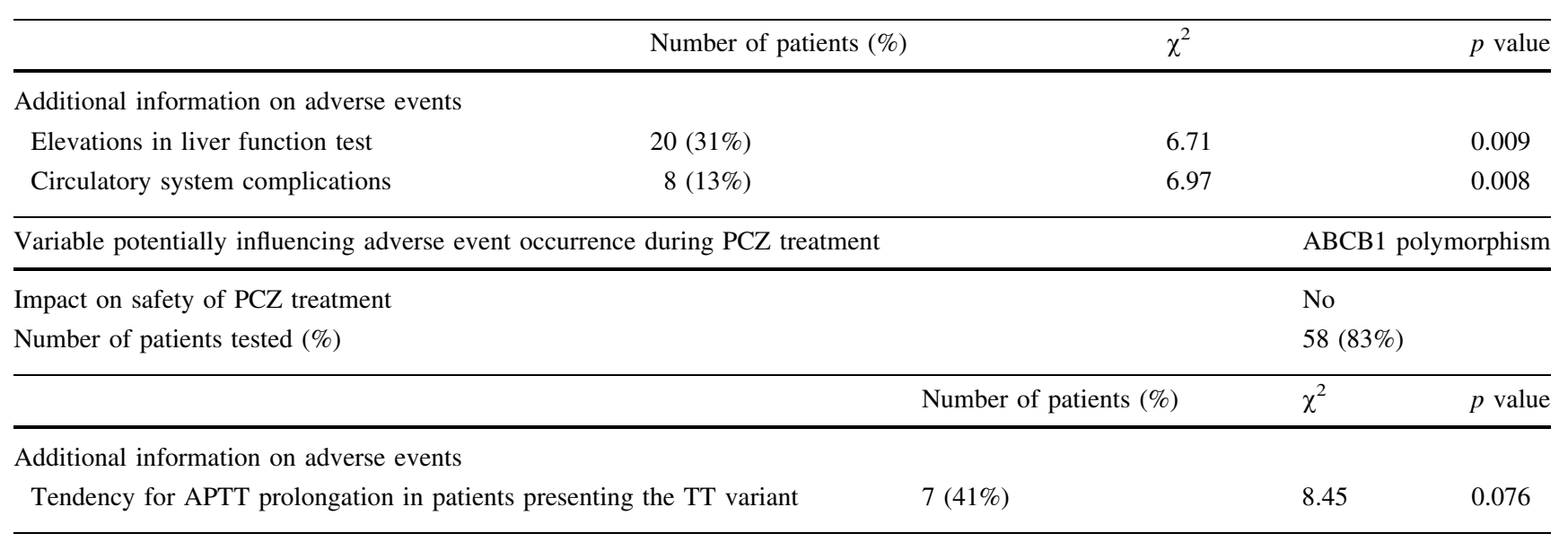


Table 5 continued

Variable potentially influencing adverse event occurrence during PCZ treatment

Concomitant cyclosporine administration

Impact on safety of PCZ treatment

No

Number of patients tested $(\%)$

$68(97 \%)$

Test

$\chi^{2}=8.75$

$p$ value $=0.271$

Variable potentially influencing adverse event occurrence during PCZ treatment

Gender

Impact on safety of PCZ treatment

No

Number of patients tested $(\%)$

$70(100 \%)$

Test

$\chi^{2}=2.61$

$p$ value $=0.919$

concentrations, during our study we observed that adverse events occurred more often in patients receiving omeprazole or pantoprazole. This could be connected with other drugs used for hematological malignancy treatment. PPIespecially the older representatives (omeprazole, pantoprazole) are CYP2C19 substrates, and therefore might affect pharmacokinetics of other drugs metabolized through CYP2C19 [20].

We observed that children with higher BMI values are more susceptible for visual and skin disturbances as well as increased LDH activity during the first week of IFI prophylaxis conducted with posaconzole. This problem was not evaluated for the pediatric population receiving PCZ in oral suspension formulation. However there is one study describing the experience from using posaconazole in form of extended released tablets. In obese adult patients (BMI $>30 \mathrm{~kg} / \mathrm{m}^{2}$, and body weight $>90 \mathrm{~kg}$ ) the antifungal agents serum levels were lower during the tablet formulation treatment [21]. Our observations are not concise with this finding. This could be due to alterations of pharmacokinetic properties of both formulations and both populations (e.g. in children the glucuronidation potential is not as high as in adults, thus it cannot be increased in childhood obesity, as it is the case in the adult population).

\section{Conclusion}

ABCB1 polymorphism has no impact on the efficiency and safety of posaconazole treatment in children with hematological malignancies. However the relatively high incidence of mild to moderate adverse events during prophylaxis, and occurrence of other factors potentially influencing PCZ pharmacokinetics such as PPI co-administration or obesity, suggest a need for careful patient evaluation and probable TDM (therapeutic drug monitoring) enrollment in onco-hematological pediatric patients receiving antifungal prophylactic treatment conducted with posaconazole oral suspension formulation.

What is certainly a limitation of our study is the relatively small group of patients and lack of posaconazole serum concentration measurement. However the aim of our retrospective research was to evaluate potential causes of $\mathrm{AE}$ occurrence, and prophylaxis failure during PCZ treatment. As our findings were partially new there is certainly a need for larger studies to evaluate the problem in the future.

Acknowledgements This study was founded by the Ministry of Science and Higher Education, Republic of Poland - the Wroclaw Medical University Grand for Young Scientists (STM.D120.16.035).

\section{Compliance with Ethical Standards}

Conflict of interest The authors declare that they have no conflict of interest.

Ethical Approval All procedures performed in studies involving human participants were in accordance with the ethical standards of the institutional and/or national research committee and with the 1964 Helsinki declaration and its later amendments or comparable ethical standards.

Informed Consent Informed consent was obtained from all individual participants included in the study.

Open Access This article is distributed under the terms of the Creative Commons Attribution 4.0 International License (http://crea tivecommons.org/licenses/by/4.0/), which permits unrestricted use, distribution, and reproduction in any medium, provided you give appropriate credit to the original author(s) and the source, provide a link to the Creative Commons license, and indicate if changes were made.

\section{References}

1. Summary of Product Characteristics Noxafil. Merck Sharp \& Dohme Limited. 2010. http://www.ema.europa.eu/docs/en_GB/ document_library/EPAR_Product_Information/human/000610/ WC500037784.pdf. Accessed 3 Jul 2018 
2. Noxafil (posaconazole)—package insert. Whitehouse Station, NJ: Merck \& Co., Inc. 2015. https://www.accessdata.fda.gov/drug satfda_docs/label/2015/022003s018s020,0205053s002s004,0205 596s001s0031bl.pdf. Accessed 3 Jul 2018

3. Lu H, Rosenbaum S (2014) Developmental pharmacokinetics in pediatric populations. J Pediatr Pharmacol Ther 19:262-276. https://doi.org/10.5863/1551-6776-19.4.262

4. Kodidela S, Kumar S, Uppugunduri CRS (2017) Developmental pattern of hepatic drug-metabolizing enzymes in pediatric population and its role in optimal drug treatment. Arch Med Health Sci 5:115-122

5. Döring M, Müller C, Johann PD, Erbacher A, Kimmig A, Schwarze CP, Lang P, Handgretinger R, Müller I (2012) Analysis of posaconazole as oral antifungal prophylaxis in pediatric patients under 12 years of age following allogeneic stem cell transplantation. BMC Infect Dis 12:263. https://doi.org/10.1186/14712334-12-263

6. Groll AH, Castagnola E, Cesaro S, Dalle JH, Engelhard D, Hope W, Roilides E, Styczynski J, Warris A, Lehrnbecher $\mathrm{T}$ et al (2014) Fourth European Conference on Infections in Leukaemia (ECIL-4): guidelines for diagnosis, prevention, and treatment of invasive fungal diseases in paediatric patients with cancer or allogeneic haemopoietic stem-cell transplantation. Lancet Oncol 15:327-340. https://doi.org/10.1016/s1470-2045(14)70017-8

7. Vicenzi EB, Calore E, Decembrino N, Berger M, Perruccio K, Carraro F, Rossin S, Putti MC, Molinaro M, Tridello G, Cesaro S (2018) Posaconazole oral dose and plasma levels in pediatric hematology-oncology patients. Eur J Haematol 100(3):315-322. https://doi.org/10.1111/ejh.13017

8. Döring M, Cabanillas Stanchi KM, Queudeville M, Feucht J, Blaeschke F, Schlegel P, Feuchtinger T, Lang P, Müller I, Handgretinger R, Heinz WJ (2017) Efficacy, safety and feasibility of antifungal prophylaxis with posaconazole tablet in paediatric patients after haematopoietic stem cell transplantation. J Cancer Res Clin Oncol 143:1281-1292. https://doi.org/10.1007/ s00432-017-2369-7

9. Welzen ME, Brüggemann RJ, Van Den Berg JM, Voogt HW, Gilissen JH, Pajkrt D, Klein N, Burger DM, Warris A (2011) A twice daily posaconazole dosing algorithm for children with chronic granulomatous disease. Pediatr Infect Dis J 30(9):794-797. https://doi.org/10.1097/INF.0b013e3182195808

10. Siegmund W, Ludwig K, Giessmann T, Dazert P, Schroeder E, Sperker B et al (2002) The effects of the human MDR1 genotype on the expression of duodenal P-glycoprotein and disposition of the probe drug talinolol. Clin Pharmacol Ther 72:572-583

11. Jamroziak K, Młynarski W, Balcerczak E, Mistygacz M, Trelinska J, Mirowski M, Bodalski J, Robak T (2004) Functional C3435T polymorphism of MDR1 gene: an impact on genetic susceptibility and clinical outcome of childhood acute lymphoblastic leukemia. Eur J Hematol 72:314-321

12. Jamroziak K, Balcerczak E, Smolewski P, Robey RW, Cebula B, Panczyk M, Kowalczyk M, Szmigielska-Kapłon A, Mirowski M, Bates SE, Robak T (2006) MDR1 (ABCB1) gene polymorphism
C3435T is associated with P-glycoprotein activity in B-cell chronic lymphocytic leukemia. Pharmacol Rep 58:720-728

13. Lehrnbecher T, Attarbaschi A, Duerken M, Garbino J, Gruhn B, Kontny U, Lüer S, Phillips R, Scholz J, Wagner HJ, Wiesel T, Groll AH (2010) Posaconazole salvage treatment in paediatric patients: a multicentre survey. Eur J Clin Microbiol Infect Dis 29:1043-1045. https://doi.org/10.1007/s10096-010-0957-4

14. Döring M, Blume O, Haufe S, Hartmann U, Kimmig A, Schwarze CP, Lang P, Handgretinger R, Müller I (2014) Comparison of itraconazole, voriconazole, and posaconazole as oral antifungal prophylaxis in pediatric patients following allogeneic hematopoietic stem cell transplantation. Eur J Clin Microbiol Infect Dis 33:629-638. https://doi.org/10.1007/s10096-013-19982

15. Ullmann AJ, Lipton JH, Vesole DH, Chandrasekar P, Langston A, Tarantolo SR, Greinix H, Morais de Azevedo W, Reddy V, Boparai N, Pedicone L, Patino H, Durrant S (2007) Posaconazole or fluconazole for prophylaxis in severe graft-versus-host Disease. N Engl J Med. 356:335-347

16. Kohl V, Müller C, Cornely OA, Abduljalil K, Fuhr U, Vehreschild JJ, Scheid C, Hallek M, Rüping MJ (2010) Factors influencing pharmacokinetics of prophylactic posaconazole in patients undergoing allogeneic stem cell transplantation. Antimicrob Agents Chemother 54(1):207-212. https://doi.org/10.1128/AAC. 01027-09

17. Li W, Zeng S, Yu LS, Zhou Q (2013) Pharmacokinetic drug interaction profile of omeprazole with adverse consequences and clinical risk management. Ther Clin Risk Manag 9:259-271. https://doi.org/10.2147/TCRM.S43151

18. Ross AL, Slain D, Cumpston A, Bryant AM, Hamadani M, Craig M (2012) Evaluation of an alternative posaconazole prophylaxis regimen in haematological malignancy patients receiving concomitant stress ulcer prophylaxis. Int $\mathrm{J}$ Antimicrob Agents 40:557-561. https://doi.org/10.1016/j.ijantimicag.2012.09.001

19. Bryant AM, Slain D, Cumpston A, Craig M (2011) A postmarketing evaluation of posaconazole plasma concentrations in neutropenic patients with haematological malignancy receiving posaconazole prophylaxis. Int J Antimicrob Agents 37:266-269. https://doi.org/10.1016/j.ijantimicag.2010.11.021

20. Gawrońska-Szklarz B, Adamiak-Giera U, Wyska E, Kurzawski M, Gornik W, Kaldonska M, Drozdzik M (2012) CYP2C19 polymorphism affects single-dose pharmacokinetics of oral pantoprazole in healthy volunteers. Eur $\mathrm{J}$ Clin Pharmacol 68:1267-1274. https://doi.org/10.1007/s00228-012-1252-3

21. Miceli MH, Perissinotti AJ, Kauffman CA, Couriel DR (2015) Serum posaconazole levels among haematological cancer patients taking extended release tablets is affected by body weight and diarrhoea: single centre retrospective analysis. Mycoses 58:432-436. https://doi.org/10.1111/myc.12339

Publisher's Note Springer Nature remains neutral with regard to jurisdictional claims in published maps and institutional affiliations. 